\title{
Measurements of Key Success Factors on Enterprise Resource Planning (ERP) Implementation
}

\author{
Gede Rasben Dantes ${ }^{1}$ and Zainal A. Hasibuan ${ }^{2}$ \\ ${ }^{1}$ Ganesha University, Singaraja, Bali, Indonesia \\ ${ }^{2}$ University of Indonesia, Depok, West Java, Indonesia
}

\begin{abstract}
Competitive Advantage is important thing that have to be considered when implement the ERP system. Most of the organization only gain operational benefit rather than create the competitive advantage. A lot of factors that influenced the success of ERP implementation in order to gain competitive advantage. One of them is the organization maturity level. We classify the organization maturity level into three levels (high to low): strategic, managerial and operational levels. In Indonesia, it is almost $70.95 \%$ companies which were implement ERP system in the managerial and operational level. It shown that organization maturity level does not automatically drive the ERP implementation. The result of the study also shows that there is no-pattern of relationship between organization maturity level and ERP implementation success. This implies that the implementation of ERP in those companies have been done trivially. On this study, we applied Spearman rank test (non-parametric) to identify significant relationships among the organization maturity level, implementation approach and ERP implementation. Thirty five respondents from seven companies were chosen as the object of the study, covering four different industrial sectors, namely: telecommunication, manufacturing, automotive and oil \& gas companies. Survey result showed that ERP Implementation Approach $\left(\mathrm{X}_{2}\right)$ has more significant influence than does the Organization Maturity Level $\left(\mathrm{X}_{1}\right)$ on ERP Implementation Success ( $\mathrm{Y}$ ). It is discovered that coefficient correlation between $\mathrm{X}_{1}$ and $\mathrm{Y}$ is 0.252 . On the other hand, the coefficient correlation between $X_{2}$ and $Y$ is 0.862 .
\end{abstract}

Keywords: Organization Maturity Level, Implementation Approach, ERP Implementation Success, Competitive Advantage

\section{Introduction}

ERP is the most popular system that are used by company to support their operational organization. It is an integrated software solution that spans the range of business processes that enables companies to gain holistic view of the business enterprise (Ehie and Madsen, 2005). It promises to integrate all business units within and/or between organizations. In the ERP implementation, a business transformation always aligns ERP's business process and company's business strategy (Esteves and Pastor, 2001). The transformation will influence company's business process improvement, cost reduction, service improvement, and minimize the effect on the company's operation (Summer, 2004). Consequently, adjustments between the business processes in the ERP system and the existence of business processes in an organization are needed to give an added value for the company.

Copyright (C) 2010. Gede Rasben Dantes and Zainal A. Hasibuan . This is an open access article distributed under the Creative Commons Attribution License unported 3.0, which permits unrestricted use, distribution, and reproduction in any medium, provided that original work is properly cited. Contact author: Gede Rasben Dantes email: rasben_dantes@yahoo.com 
However, the implementation of this system is not always proven beneficial. Dantes (2006) found out that in Indonesia, almost $83.33 \%$ of companies implementing the ERP system did not succeed in their implementations. Although the failure rate of these ERP implementations have been highly publicized, this has not distracted companies from investing large sum of money on ERP system (Ehie and Madsen, 2005). These failures did not lie on the incorrect coding of the ERP software, but on the failure of the companies to match the true organizational needs and systems required to solve the business problems. Various factors may influence the ERP implementation success, such as: organization maturity level, implementation approach, organizational culture, organization's business process, top management commitment and others external factors. A number of studies have been conducted to find the key factors to ERP implementation success (Tsai et.al., 2005; Nah et.al., 2001; Somers and Nelson, 2004; Gargeya and Brady, 2005; Ehie and Madsen, 2005, Bhatti, 2005; Chung et.al., 2008) while some other studies had also tried to evaluate it (Motwani et.al., 2005; Brown and Vessey, 1999; Dantes, 2006; Carton and Adam, 2003; Barki et.al., 2005; Gunson and de Blasis, 2002).

Most of Indonesian companies have not yet been mature in term of the IS role in their organization. Is it the reason for the failure on ERP implementation? Or whether the ERP Implementation Approach has contributed to this failure? How is the relationship among organization maturity level $\left(X_{1}\right)$, implementation approach $\left(X_{2}\right)$ and the ERP implementation success (Y). On this study will explore these questions and try to find the coefficient correlation among $X_{1}, X_{2}$ and $Y$ using the Spearman rank test. The result of the study can be used by the organization to increase probability of ERP implementation success.
The findings are also expected to improve knowledge in Enterprise System, Management Information System and measurements of key success factors on ERP implementation.

\section{Theoretical Framework}

The following section reviews a number studies concerning organization maturity level, ERP implementation approach, and the relationship between ERP and organizational hierarchies.

\section{Organization Maturity Level}

Organization maturity level (OML) has the most significant impact on the implementation of this system. The higher the maturity level of an organization, the higher probability of ERP implementation success will be reached by the company. But that's may not always the case. Other factors may influenced as well.

The organization maturity level can be categorized into three levels: operational, managerial and strategic (Shang and Seddon, 2002). These categories are based on IS roles in an organization. In the operational level, any IS has several indicators: cost reduction, cycle time reduction, productivity improvement, quality improvement and customer service improvement. In managerial level, the indicators include better resource management, improve decision making \& planning, and performance improvement. However, in strategic level, the IS indicators are: support business growth, support business alliance, build business innovation, built cost leadership, generate product differentiation, and build external linkage (see figure 1). Therefore, an organization with a higher maturity level is more probable to success on the implementation of ERP system. 


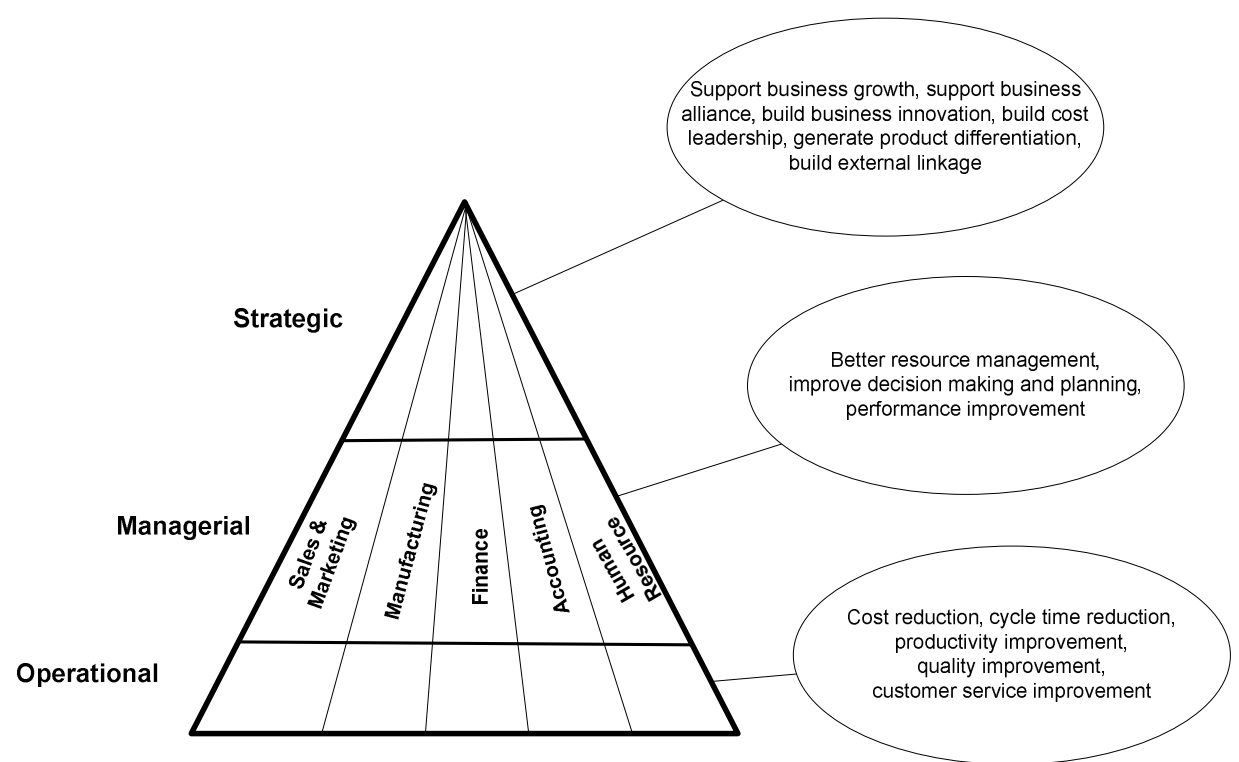

Figure 1. The Organization Maturity Level base on Information System Role

\section{ERP Implementation Approach}

ERP system selection is not a simple process. It begins from identification of system scope, a business objective and an organization business process. There are two approaches which are most often applied in system implementation (O'Leary, 2000), there are: (1) Business Process Reengineering (BPR) drives ERP implementation, and (2) ERP implementation drives BPR.

The BPR drives ERP implementation approach is usually used by the organization with a mature business process. Therefore, the reengineering of a business process will drive a requirement for information system that support an organization's day-to-day activities. On the other hand, this approach is used by organization to create a competitive advantage. The other ERP implementation approach used by the organization without a mature business process. Thus, the ERP business process will become a reference when it has reengineered the organization's business process. Both approaches have a strong relationship with organization maturity level.

The implementation approach (ERP drives BPR) can be done in two ways (O'Leary, 2000), (1) minimum software change and minimum process change or (2) minimum software change and maximum process change. On the other hand, the second implementation approach (BPR drives ERP) can be done in two ways: (1) maximum process change and maximum software change or (2) minimum process change and maximum software change.

Doing Business Process Reengineering (BPR) before choosing one of ERP product is an ideal implementation approach in ERP implementation (O'Leary, 2000). Therefore, we can choose the ERP product that suitable with an organization's business process. This method will make a maximum process and software change. Although this method has a big potentiality of implementation failure, but a successful implementation will give an optimal benefit, and possibly a competitive benefit as well.

\section{ERP and Organization}

ERP as an integrated information system involves all level of organization hierarchy, including (see figure 2): transaction processing system (TPS), management information system (MIS) and executive information system (EIS) (Ward and Peppard, 2003). ERP has some standard modules as well as the specific ones. Standard modules contains: material 
management, production planning, finance \& controlling, sales \& distribution, human resource, etc. These modules lay on TPS level. On the next level, ERP has a business warehouse (BW) module that can consolidate all transaction data. In this level we need a query or reporting to get an information that more easier to understand by management level. On the EIS level, ERP has a business intelligent (BI) to get the valuable information from data warehouse/data mart. This information will be used to help the top management level to make an organization decision.

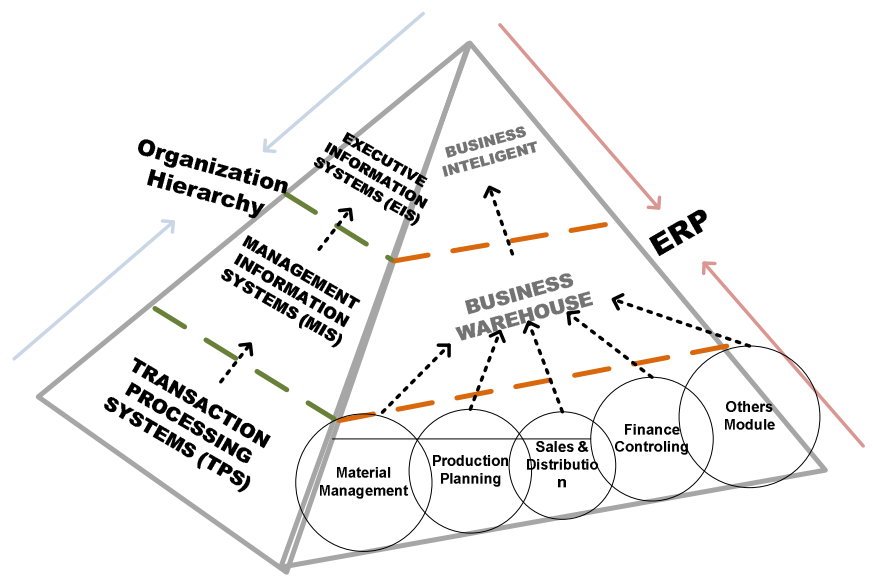

Figure 2. ERP and Organization Maturity Level

(Source: Dantes \& Hasibuan, 2009)

\section{Research Methodology}

The key objective of this study was to examine a number of issues regarding the relationship between organization maturity level $\left(\mathrm{X}_{1}\right)$, ERP implementation approach $\left(\mathrm{X}_{2}\right)$ and ERP implementation success $(\mathrm{Y})$.

Organization maturity level $\left(\mathrm{X}_{1}\right)$ is the score of the role of information system (IS) in a company (Shang and Seddon, 2002). The organization maturity level includes operational, managerial and strategic as explained above. Each level has some measurement indicators for mapping each organization into this maturity level. ERP implementation approach $\left(\mathrm{X}_{2}\right)$ is the score of the approach adopted in ERP implementation whether by conducting business process reengineering (BPR) prior to ERP implementation or implementation of ERP system first before the organization implements BPR.

The success in ERP implementation is the score for the success or lack of success in its implementation in a company. The indicators measured include cost and time of implementation (Iskanius, 2009), performance and benefit obtained. In this study, we classify level of success into four, namely: (1) high success, that if all indicators are met; (2) success, that if only performance and benefit indicators are met; (3) low success, if cost and time indicators are met; and (4) fail, if none of the indicators are met. This success of implementation is taken from the organization point of view, in which the organization is the project owner. The constellations of the variables above are illustrated in figure 3. 


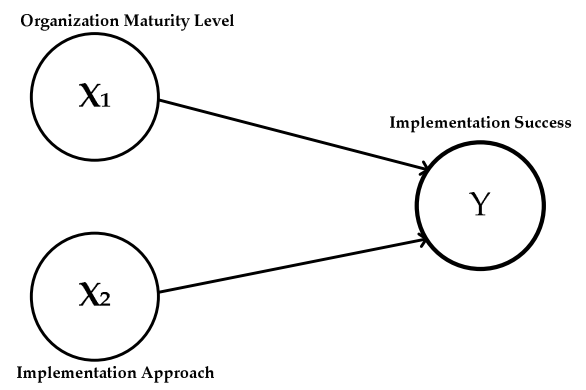

Figure 3. The Hypothetical Model of the Relationship between Organization Maturity and ERP Implementation Approach Toward Implementation Success

As a preliminary study, the research covered seven companies which have been implementing ERP system to support their operational. These seven companies include four different industrial sectors, namely: telecommunication, manufacturing, automotive and oil \& gas company.

To address the study objectives, a survey questionnaire was considered the most appropriate research methodology. It was sent to seven companies that have been implemented ERP system at least one year. There are top five companies in their respective industrial sectors. The practical samples were company's management level, ERP consultants, IT staff and users involved in the development and use of ERP system. The survey received 35 responses from 70 quesitionnaire that are sent to the company as preliminary study.

Table 1: Research Sample base on Industrial Sector

\begin{tabular}{|c|l|c|}
\hline No. & \multicolumn{1}{|c|}{ Industrial Sector } & Number of organization \\
\hline 1. & Telecommunication & 2 \\
\hline 2. & Manufacturing & 3 \\
\hline 3. & Automotive & 1 \\
\hline 4. & Oil \& Gas & 1 \\
\hline \multicolumn{2}{|c|}{$\sum$ organization as a sample } & 7 \\
\hline
\end{tabular}

Other than the questionnaire, the present study also conducted interviews and document observation to support the research data. Interviews were conducted with several ERP consultants at the level of technical as well as functional, IT Staffs, and with users involved in the ERP implementations in each of the seven companies. The interviews were conducted in structured and unstructured methods. The questions posed were focused on: (1) the organization maturity level, (2) implementation approach, (3) the factors driving ERP implementation (4) the benefits or competitive advantages gained.

\section{Result and Discussion}

This section discuss the evaluation of ERP implementation in Indonesia, namely: (1) organization maturity level for those Indonesian companies that implemented ERP system, (2) implementation approach that are used by the Indonesian companies to adopt ERP system, (3) ERP implementation success and (4) the relationship between organization maturity and ERP implementation success. 
Organization Maturity Level and ERP Implementation Success

The following findings are the outcome of the surveys conducted in the seven Indonesian companies which have been implementing ERP. The following table exposes the survey results concerning the three variables involved in this study: the organization maturity level, implementation approach and ERP implementation success.

Table 2: Survey Result

\begin{tabular}{l} 
Organization Maturity Lev \\
\hline Strategic \\
\hline Support Business Growth \\
Support Business Alliance \\
Build Business Innovation \\
Build Cost Leadership \\
General Product \\
Differentiation Sub Total \\
Managerial \\
Better Resource \\
Management \\
Improve Decision Making
\end{tabular}

el $\left(\mathbf{X}_{1}\right)$ Percent

8.78

4.73

4.73

8.11

2.70

29.05

11.49

10.81

Sub Total

22.30

\section{Operational}

Cost Reduction

Cycle Time Reduction

Productivity

Improvement

Quality Improvement

Customer Service

Improvement

Sub Total
10.13

9.46

10.81

7.43

10.81

The findings show that when a company has higher organization maturity level, then IS/IT owned by the company does not only act as support. But, IS/IT will be an enabler for the company in which it can be expected to create competitive advantage.

Thus, companies whose organization maturity lay on the strategic level are expected to adopt ERP system successfully. This imply that companies whose organization maturity are below strategic level (in other words at operational/managerial level), they are supposed to carry out internal business process improvement before implementing ERP system. This step will drive the companies to advance to the higher maturity level. However, the success of ERP

Implementation Approach

\begin{tabular}{lc}
$\left(\mathbf{X}_{2}\right)$ & \\
\hline & Percent \\
\hline Business need & 9.09 \\
Meet Org. Business Flow & 19.70 \\
Process Change & 16.67 \\
Meet Org. Business Practices & 19.70 \\
BPR drive ERP & 7.58 \\
ERP drive BPR & 10.61 \\
Business Process & 16.67 \\
Improvement &
\end{tabular}

\section{ERP Implementation}

Success (Y)

\begin{tabular}{lc}
\hline & Percent \\
\hline Cost & 28.57 \\
Time Schedule & 39.29 \\
Performance & 21.43 \\
Benefit & 10.72
\end{tabular}

system adoption cannot be measured only from the organization maturity level. There are other factors that can influence the ERP implementation success, such as: organizational culture, organization readiness, human resources skill, organization's business strategy, organization's business process, etc (Brown and Vessey, 1999; Hong and Kim, 2002; Molla and Loukis, 2005; Viehland and Shakir, 2005; Wenrich and Ahmad, 2009).

There are several aspects that show linear correlation with organization maturity level. As noted before, organization maturity level reflects the organization's readiness to adopt new technology. This also reflects the human resourcess skill, 
organization's mature business process, and a good organizational culture within that organization. It found that only $29.05 \%$ of the companies implementing ERP were on the strategic organization maturity level, $22.30 \%$ were still on the managerial level and $48.65 \%$ are on operational level. It is also found that coefficient correlation between organization maturity level $\left(\mathrm{X}_{1}\right)$ and ERP Implementation Success (Y) is 0.252 (see table 3). It implies that both of variables do not have a significant correlation with $\mathrm{p}<0.05$. There are several significant things to note on the domain of this organization maturity level, namely: insufficient of the IS roles in supporting business networks with other companies, inadequate of the IS in creating innovations for the company's business, and the weakness of the IS in generating new product differentiations in the market.

The above data also show that the companies in Indonesia do not consider organization maturity as the point of reference in adopting ERP system, hence the failure in the ERP implementation. It should be acknowledged that ERP sistem is a technology that requires large investment and thus it requires the organization's promptness in adopting it. This promptness covers readiness of the organizational culture, human resource skill, mature business process, etc. ERP implementation in Indonesia, however, the decision to implement ERP is driven more by the trend in technology rather than the organization's business needs. This, most possibly, is caused by the perception hold by the company which believes that ERP is a technology that would solve every problem, internal and external organization.

Other than this presumption, there are also other reasons driving ERP implementation in Indonesia: such as: (1) to raise the company's rate at the domestic stock market since implementation of IS/IT would assume transparation, accuntability, accuration of the company's data; (2) to increase customer's confidence; (3) bank policies, which force company as creditor to implement sufficient IS/IT (i.e. ERP system); (4) relationship between project owner and ERP vendor; and other external factors (Dantes, 2006; Dantes and Hasibuan, 2009).

As mentioned before, non-significant correlation between organization maturity level and ERP implementation success shows that high-level of organization maturity does not always assure success in the implementation of ERP. This correlation can be illustrated by Figure 4 . This graphic shows that there is no-pattern of relationship between organization maturity level and ERP implementation success. This pattern indicates that the ERP implementation in Indonesian companies are done in trivial process rather than designed in accordance with the IS/IT plan owned by the companies. This is the most significant factor that influences ERP implementation success in Indonesia.

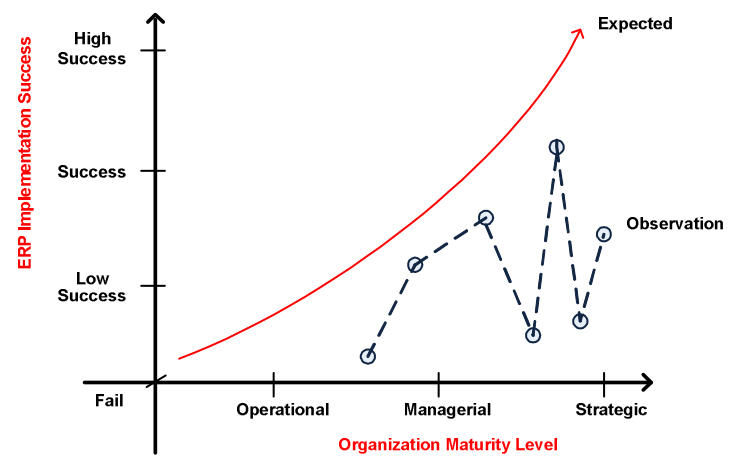

Figure 4. The Relationship of Organization Maturity Level and ERP Implementation Success 


\section{ERP Implementation Approach}

As much as $38.89 \%$ of the respondents of the questionnaires stated that the approach applied in implementing ERP in their companies was the ERP drives BPR. According to (O'Leary, 2000), ERP drives BPR approach can be conducted in one of these two ways: (1) minimum changes in software and process, or (2) minimum changes in software and maximum changes in process. Either way is an effort to minimize failure.

As much as $27.78 \%$ of the respondents stated that their companies applied BPR drives ERP approach. This approach can be done in one of these two ways: (1) maximum changes in process and software, or (2) maximum changes in software and minimum changes in process (O'Leary, 2000 ). The rest $33.33 \%$ of the respondents stated that they were not clear with the approach employed for the ERP implementation in their companies.

The most ideal approach in implementing ERP system is by doing BPR before deciding on selection of the technology that suits the organization's business process. This step also enables maximum changes in process and software. Even when ERP implementation has wide possibility to fail, this approach will give trade off to the company if the implementation runs smoothly. Such company will become the first mover in adopting this technology and thus the company has a better competitive position among its competitors.

However, not every company can apply this implementation approach. The companies that can launch such implementation are the companies whose strong financial, can provide sufficient time for the implementation, and those company whose vision is to create strategy advantage and to find unique solutions for their business (O'Leary, 2000; Porter, 1985; Davenport, 2000). Whereas small and medium enterprises usually conduct BPR after implementing ERP, which is usually termed technology enable approach. These companies are usually those with mediocre budget and standard business process.

In line with (O'Leary, 2000) arguments, it can be stated that most of Indonesian companies under investigation applied the ERP drives BPR approach in which minimum changes of software and process are required. These companies would do minimum changes to the ERP system in the process of making it in align with the existing business process. Other than to minimize failure, this approach is also taken due to the difficulties in doing maximum process changes. This is related to the employee's resistance in accepting the changes in the business process. Changes in business process will have to give impact to changes in working habits and to the possibilities of mutations from one business unit to another as well as employees downsizing (Remenyi et.al., 2000; Barki et.al., 2005).

It is indeed a tight spot for companies in Indonesia in doing BPR. On one hand, these companies have to improve their productivity and efficiency, while on the other hand, they have to consider the number of employees who have to lose their jobs when new technologies applied by the companies need less hands to take care. Nevertheless, it is important to note that ERP implementation is not only an adoption of a new technology. This is a business transformation where process changes are very critical components (Molla and Loukis, 2005; Bosilj-Vuksic and Spremic, 2004). Thus, the change management is very crucial in every ERP implementation. 
Table 3: Spearman Rank Test Matrix of All Variables ( $\mathrm{N}=35)$

\begin{tabular}{|c|c|c|c|}
\hline 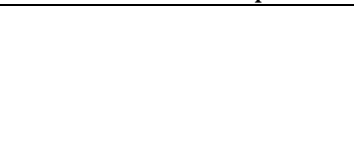 & $\begin{array}{c}\text { Organization } \\
\text { Maturity } \\
\text { Level } \\
\left(\mathrm{X}_{1}\right)\end{array}$ & $\begin{array}{c}\text { ERP } \\
\text { Implementati } \\
\text { on Approach } \\
\left(X_{2}\right)\end{array}$ & $\begin{array}{c}\text { ERP } \\
\text { Implementati } \\
\text { on Success } \\
\text { (Y) }\end{array}$ \\
\hline $\begin{array}{c}\text { Organization Maturity } \\
\text { Level }\left(X_{1}\right)\end{array}$ & $x_{1-18}$ & $e_{-2}(-2)$ & $x_{1}$ \\
\hline $\begin{array}{c}\text { ERP Implementation } \\
\text { Approach }\left(\mathrm{X}_{2}\right)\end{array}$ & - & - & - \\
\hline $\begin{array}{l}\text { ERP Implementation } \\
\text { Success (Y) }\end{array}$ & $0.252^{* *}$ & $0.862^{*}$ & - \\
\hline
\end{tabular}

\section{ERP Implementation Success}

Up to $28.89 \%$ of the respondents stated that the ERP implementation met within budget, $39.29 \%$ stated that it met the time schedule, $21.43 \%$ stated that it met the system performance, and only $10.72 \%$ stated that the ERP implementation met with the benefit as expected. It also found that implementation approach has more significant impact on the success of implementation than the organization maturity level. It has been proven that coefficient correlation between ERP implementation approach $\left(\mathrm{X}_{2}\right)$ and ERP implementation success (Y) is 0.862 (see table 3). It implies that both of variables have a significant correlation with $\mathrm{p}<0.01$. As mentioned before, ERP implementation will have highest success potentiality when the company conducts a minimum process change and minimum software change. The consequence is that ERP is only a support the core business for the company without giving optimal return value for the company implementing it.

Thus, with the companies implementing ERP in Indonesia, the factors contributing to the failure of the implementation can be summed up into ten factors: (1) the budget allocation and project schedule were not designed accurately; (2) there were changes of request when implementation project was in progress; (3) there was not any optimal support both from users and key users; (4) good communication between internal project leader and ERP consultant was not established; (5) there were changes in the consultant staffs; (6) the consultants' skills did not met the internal project leader's expectations (7) there were mistrust to the new system because users kept comparing the ERP system with the legacy system in terms of performance; (8) inadequate hardware to go with the software complexity contributes to low performance of the new system; (9) users showed lack of discipline in doing data entry, and (10) there were inconsistence of data due to ERP software changes.

Other than the above factors, there is also one important thing that needs to be considered in ERP implementation: the process of software selection (Carton and Adam, 2003; Chung et.al., 2008). Most of the companies ignored the strategy and business process in selecting software for ERP implementation. Companies were inclined to see the diverse functions and features offered by this software without doing critical evaluations on the impacts of such software implementation. Following trend in technology and business generally became major priority in choosing ERP without relating it with its impact on human and organization cost.

\section{Conclusion}

Based on the analysis, it can be concluded that $29.05 \%$ of the companies that have been implementing ERP were at the strategic level while $70.95 \%$ were at the managerial level and operational level. This indicates that organization maturity level does not become the point of reference for adopting ERP system. The main reason that Indonesian companies implement ERP more toward perception that ERP can solved all companies problems. Another 
reason is that such implementation would increase the companies' rating in the domestic stock market and it can improve public confidence toward the companies. This is based on the perception that when a company applies ERP, it will have high transparency, accountability, and accuracy concerning the company's profile.

Regarding the implementation approach, Indonesian companies tend to employ ERP drives BPR approach. As much as 38.89\% of the respondents stated that their company applied ERP drives BPR; another $27.78 \%$ stated that their company employed BPR drive ERP approach while the rest of it $-33.33 \%$ of the respondent were not sure about the approach employed by their company. This tendency shows that the companies wanted to minimize failure in the ERP implementation. But, as much as $83.33 \%$ of the Indonesian companies under investigation "not success" in their ERP implementation (Dantes, 2006). The main reason of this failure is that ERP implementation was conducted in trivial process without a sufficient planning. This trivial process may due to cultures and the nature of industrial variation.

Refering to objective of this study, it found that ERP implementation approach $\left(\mathrm{X}_{2}\right)$ has more significant influence to ERP implementation success (Y) than organization maturity level $\left(\mathrm{X}_{1}\right)$. It has been proven that the coefficient correlation between $\mathrm{X}_{2}$ and $\mathrm{Y}$ is 0.862 . However, the coefficient correlation between $\mathrm{X}_{1}$ and $\mathrm{Y}$ is 0.252 . Therefore, before implementing ERP system, it is highly recommended that a company improve its maturity level and this company has to choose the most suitable ERP implementation approach that meets the company's needs and conditions. The result of this study can be used by any organization to increase probability of ERP implementation success. The findings are also expected to improve knowledge in Enterprise System, Management Information System and measurements of key success factors on ERP implementation.

\section{Future Research}

In line with the findings of the present study concerning the reasons behind the failure of the ERP implementation in the seven Indonesian companies under investigation, more thorough analysis on ERP implementation approach is needed. There is also a critical need for the development of ERP implementation methodology that will embrace the organizational culture and variation of industrial sectors in Indonesia.

\section{References}

Barki H. et al. (2005), 'Dimensions of ERP Implementations and Their Impact on ERP Project Outcomes', Journal of Information Technology Management XVI(1).

Bhatti T.R. (2005), 'Critical Success Factors for The Implementation of Enterprise Resource Planning (ERP): Empirical Validation', The Second International Conference on Innovation in Information Technology (IIT).

Bosilj-Vuksic V. and Spremic M. (2004), 'ERP System Implementation and Business Process Change: Case Study of a Pharmaceutical Company', Journal of Computing and Information Technology.

Brown C. and Vessey I. (1999), 'Managing the Next Wave of Enterprise Systems: Leveraging Lessons from ERP', MIS Quarterly Executive.

Carton F. and Adam F. (2003), 'Analysing the Impact of Enterprise Resource Planning Systems Roll-outs in Multi-National Companies', Electronic Journal of Information Systems Evaluation, 6(2), 21-32.

Chung B.Y. et al. (2008), 'Analyzing Enterprise Resource Planning System Implementation Success Factors in the Engineering - Construction Industry', Journal of Computing in Civil Engineering, $373-382$.

Dantes G.R. (2006), 'ERP Implementation and Its Impact for Human \& Organizational Cost', M.S. Thesis, University of Indonesia, Jakarta, Indonesia.

Dantes G.R. and Hasibuan Z.A. (2009), 'Multi-Factors Enterprise System Methodology: An Approach to ERP Implementation', International Conference 
on Creative Communication and Innovative Technology, Jakarta.

Davenport T.H. (2000), Mission Critical (Realizing The Promise of Enterprise Systems). Boston, Massachusetts, Harvard Business School Press.

Ehie I.C. and Madsen M. (2005), 'Identifying Critical Issues in Enterprise Resource Planning (ERP) Implementation', Computers in Industry, 56, 545-557.

Esteves J. and Pastor J. (2001), 'Enterprise Resource Planning Systems Research: An Annotated Bibliography', Communications of the Association for Information Systems, $7(8)$.

Gargeya V.B. and Brady C. (2005), 'Success and Failure Factor of Adopting SAP in ERP System Implementation', Business Process Management Journal, 11(5), 501-516.

Gunson J. and de Blasis J.P. (2002), 'Implementing ERP in Multinational Companies: Their Effect on the Organization and Individuals at Work', Journal ICT.

Hong K.-K. and Kim Y.-G. (2002), 'The Critical Success Factor for ERP Implementation an Organizational Fit Perspective', Information \& Management Journal, Volume 40.

Iskanius P. (2009), 'The ERP Project Risk Assesment - A Case Study. World Congress on Engineering', London, UK.

Molla A. and Loukis I. (2005), Success and Failure of ERP Technology Transfer: A Framework for Analyzing Congruence of Host and System Culture, Development Informatics Working Paper Series.

Motwani J., Akbul A.Y., and Nidumolu V. (2005), 'Successful Implementation of ERP Systems: A Case Study of an International Automotive Manufacturer', International Journal of Automotive Technology and Management, 5(4), 375-386.

Nah F. F.-H et.al. (2001), 'Critical Factors for Successfull Implementation of Enterprise Systems', Business Process Management, 7(3), 285-296.
O'Leary D.E. (2000), Enterprise Resource Planning System (Systems, Life Cycle, Electronic Commerce, and Risk), Cambridge University Press, Cambridge.

Porter M.E. (1985), Competitive Advantage (Creating and Sustaining Superior Performance), The Free Press, New York.

Remenyi D., Arthur M., and SherwoodSmith M. (2000), The Effective Measurement and Management of IT Costs and Benefits, 2nd Edition, Elsevier, Burlington.

Shang S. and Seddon P. (2002), 'Assessing and Managing the Benefits of Enterprise

Systems: the Business Manager's Perspective', Information Systems Journal, 12,271-299.

Somers T.M. and Nelson K.G. (2004), 'A Taxonomy of Players and Activities Across the ERP Project Life Cycle', Information and Management.

Summer M. (2004), Enterprise Resource Planning, Upper Saddle River, New Jersey.

Tsai W, Chien S., Hsu P., and Leu J. (2005), 'Identification of Critical Failure Factors in the Implementation of Enterprise Resource Planning (ERP) System in Taiwan's Industries', International Journal of Management and Enterprise Development.

Tsai C.-H. et al. (2005), 'A Case Study of ERP Implementation for Opto-Electronic Industry', International Journal of The Computer, The Internet and Management, 13(1), 13-30.

Viehland D. and Shakir M. (2005), 'Making Sense of Enterprise System Implementation', Business Review, 7(2).

Ward J. and Peppard J. (2003), Strategic Planning for Information System, $3^{\text {rd }}$ Edition, John Wiley \& Sons, Chicester.

Wenrich K.I. and Ahmad N. (2009), 'Leason Learned During a Decade of ERP Experience: A Case Study', International Journal of Enterprise Information Systems, $5(1)$ 